International Journal of Current Advanced Research

ISSN: O: 2319-6475, ISSN: P: 2319 - 6505, Impact Factor: SJIF: 5.995

Available Online at www.journalijcar.org

Volume 6; Issue 4; April 2017; Page No. 3333-3336

DOI: http://dx.doi.org/10.24327/ijcar.2017.3336.0265

\title{
A REVIEW ON CROSS INFECTION IN DENTAL CLINICS
}

\author{
Anisha Mahtani ${ }^{1}$ and Gopinath $\mathbf{P}^{2 *}$
}

${ }^{1}$ BDS 2nd year, Saveetha Dental College, Chennai

2Department of Microbiology, Saveetha Dental College, Chennai

\section{A R T I C L E I N F O}

\section{Article History:}

Received $26^{\text {th }}$ January, 2017

Received in revised form $10^{\text {th }}$ February, 2017

Accepted $22^{\text {nd }}$ March, 2017

Published online $28^{\text {th }}$ April, 2017

\section{Key words:}

Infection, hygiene, sterilization, disinfection, saliva

\begin{abstract}
A B S T R A C T
Aim: To write a review on cross infection in dental clinics.

Background: Cross infection is the transfer of harmful microorganisms usually bacteria and viruses between patients. The spread of infection may be direct or indirect. Indirectly the infection can spread through contaminated hand pieces and aerosols. Most carriers of infections are unaware of their condition and therefore it is important that prevention of cross infection routine is adopted for all patients.

Materials and Methods: Reviews on cross infection in dental clinics were collected from Journals with a PubMED, Science Direct and Scopus Index. Results: The articles collected were about the modes of transmission and the prevention and control measures on cross infection in dental clinics around the world.
\end{abstract}

Copyright $\bigcirc 2017$ Anisha Mahtani and Gopinath P. This is an open access article distributed under the Creative Commons Attribution License, which permits unrestricted use, distribution, and reproduction in any medium, provided the original work is properly cited.

\section{INTRODUCTION}

\section{What is cross infection?}

Cross infection can be defined as the transmission of infectious agents between patient and staff within a clinical environment. ${ }^{[1]}$ Transmission may result from a person to person via contaminated objects. Transmission of infection from one person to another requires a source if infection. The infective agent is transmitted through blood, droplets of saliva and instruments contaminated with saliva, blood and tissue debris. ${ }^{[2]}$ The patient's oral microorganisms can be spread either by direct or indirect contact, droplet inhalation, or by inoculation. The risk of transmission or hepatitis $\mathrm{C}$ is not fully evaluated, but dental personnel have a high frequency of antibodies to this virus, suggesting that exposure has occurred. Failure to adequately clean, disinfect and/or sterilize dental instruments contaminated with pathogenic organisms from a previous patient will endanger subsequent patient. [3] This route of pathogenic microorganisms transfer is known as cross-contamination and the resulting infection is referred to as cross-infection. The highest potential for cross infection is between dentists, surgery assistants and patients because blood, saliva and contaminated instruments are present.

\section{Modes of Transmission}

Due to the nature of their profession, dentists and dental assistants should not forget the risk of treating patients with

\section{*Corresponding author: Gopinath $\mathbf{P}$}

Department of Microbiology, Saveetha Dental College, Chennai and patients may be exposed to pathogenic microorganisms localized in oral cavity and respiratory tract including cytomegalovirus (CMV), HBV, HCV, herpes simplex virus (HSV) type 1 and 2, HIV, Mycobacterium tuberculosis, staphylococci, streptococci and other viruses and bacteria ${ }^{4}$ Research has shown that infective hazards are present in dental practice, because many infections can be transmitted by blood or saliva through direct or indirect contact, droplets, aerosols, or contaminated instruments and equipment. ${ }^{5}$ All dental personnel are at risk, including dentists, nurses, and hygienists, who may transmit infectious diseases to patients by the use of contaminated dental instruments or hands.

Previous seroepidemiological studies have confirmed these occupational hazards, showing higher concentrations of serum antigen and antibodies for hepatitis $\mathrm{B},{ }^{6,9}$ hepatitis $\mathrm{C},{ }^{10,11}$ and Legionella spp, ${ }^{12}$ in dentists than in the lay population and an increased prevalence of respiratory infections ${ }^{13}$ and symptoms ${ }^{14}$ possibly related to aerosols. Previous studies have shown extensive contamination of water in dental units, not only with water saprophytes, but also with some potentially pathogenic microorganisms such as Legionella pneumophila, ${ }^{15}$ and Pseudomonas aeruginosa. ${ }^{16,17}$ Bacterial counts as high as tens of millions of colony forming units $/ \mathrm{ml}$ $(\mathrm{cfu} / \mathrm{ml})$ have been reported. These counts far exceed the 200 $\mathrm{cfu} / \mathrm{ml}$ goal for aerobic mesophilic bacteria suggested by the American Dental Association for dental surgery. ${ }^{18}$

Concerns about control of infection in dentistry have been heightened by a report of transmission of human immunodeficiency virus (HIV) from an American dentist to five of his patients. ${ }^{19,20}$ Centers for Disease Control and Prevention. Possible trans- mission of human 
immunodeficiency virus to a patient during an invasive dental procedure.

There is compelling evidence, however, that six patients of an HIV-infected dentist from Florida were infected with HIV at the dental practice. The dentist's HIV strain and that of the patients was virtually identical and the patients possessed no other risk factors for HIV. ${ }^{[21]}$

\section{Prevention}

The use of procedures to control infection and universal precautions in the dental surgery is effective in preventing microbial pollution and cross contamination and is strongly supported by organizations such as the Centers for Disease Control and Prevention, the American Dental Association, schools of dentistry, and many other health agencies and professional associations. ${ }^{22}$ There are basic standards set for the prevention and control of infections in the dental workplace. These include vaccination against hepatitis B virus, use of protective barriers, sterilization of all invasive instruments and taking a thorough medical history for all patients. ${ }^{[23]}$

Early studies indicate that compliance of the dentist with these guidelines was not satisfactory. ${ }^{[24,25]}$ One of the factors that can bring about change in compliance is patient's expectation. This expectation can be influenced by the media, cultural mores, as well as the patient's level of education. ${ }^{[26]}$ One aspect of infection control that a patient can assess is the use of barrier materials such as gloves and surgical facemasks. It is important that patients recognize the need for use of these materials during dental treatment and feel comfortable when the dentist uses such materials. Some dentists have actually indicated that patients unease with the use of these materials is a factor in non-compliance with their use.

Knowledge of patients regarding sterilization methods used in the dental clinic was assessed by indicating one or more of five different methods listed. Eighty- two (36\%) of the respondents felt that instruments should be sterilized by boiling, while $29.3 \%(n=67)$ had no idea of how instruments should be sterilized. There are two reasons why dental health care workers must wear operating gloves: to prevent transmission of infection from the operator's hands to the patients, and to prevent contact of blood and saliva with the operator's hands ${ }^{27}$

The study conducted by O Sofola, O G Uti and Onigbinde Lagos, Nigeria reveals the relative ignorance of Nigerians on measures for preventing cross-infection in the dental clinic. There is evidence of high frequency of use of gloves by dentists $(83.6 \%)$ compared with theof use facemasks $(37.1 \%)$. This may be a factor of unavailability as it was found that the private dental clinic had a significantly higher frequency of usage compared with the public hospitals. ${ }^{[23]}$

Patientsattitude to the use of the barrier methods could also be a determining factor. The use of gloves was popular among the patients in this study. Almost all, 98.6\% $(n=225)$ considered the use of gloves as 8 necessary and in other studies nearly $60 \%$ of all respondents expected the dentist to wear a new set of gloves while treating each patient. ${ }^{[2]}$

The potential air contamination of dental surgeries by infectious aerosols has also been pointed out by the Centers for Disease Control and Prevention in Atlanta, which recommend that all sources of blood contaminated splatter and aerosols be minimized with rubber dams, high velocity evacuation, and proper positioning of the patient. ${ }^{[28]}$

To minimize the risk of cross infection in the dental office, specific recommendations have been issued by professional health agencies. These recommendations include routine use of barrier techniques (gloves, masks), heat sterilization of dental instruments, vaccination against $\mathrm{HBV}$, and the universal precautions. Dentists' compliance with these recommendations and infection control programs (ICP) has been recently studied in different parts of the world. ${ }^{29,30,31}$ These investigations indicate that there are gaps in some dentists' knowledge regarding modes of transmission of infectious diseases, the risk of infection from needle stick injuries, and awareness that general measures that protect against HBV transmission are sufficient to protect against HIV. However, dentists working in hospitals and dental schools are more likely to adhere to ICP than private sector dentists because institutions usually have occupational health policies related to infection control. ${ }^{32}$ The role of the dental assistant is vital to the process of infection control; however, the adherence of this particular group to these guidelines is inadequate because they receive less formal training than provided for dentists. ${ }^{33}$

Infection control forms an important part of practice for all health care professions and remains one of the most costbeneficial medical interventions available. ${ }^{32}$ This is the first study conducted to assess the compliance of general dentists working in private clinics in Jordan with infection control procedures that are designed to reduce the risk of transmission of a variety of microorganisms to dental team and patients. We studied infection control in private clinics because they often lack hazard risk instructions or occupational health policies that are more commonly available in universities and hospitals.

The response rate to the questionnaire in this study (91.66 percent) was higher than or comparable to previous studies. ${ }^{32,33}$ This high rate is due to the importance of the issue of infection control in dental practice. ${ }^{[34]}$ Despite the fact that all DHCW should wear gloves to prevent the transmission of infection to patients and to prevent the contact of the operator's hand with blood and saliva, only 81.8 percent of dentists in this study reported that they wore and changed gloves. $^{[34]}$ In this study, 54.5 percent $(60 / 110)$ wore and changed masks during treatment and between patients, in comparison to 75 percent in Kuwait, ${ }^{7} 64.8$ percent in New Zealand, ${ }^{35} 74.8$ percent in Canada, ${ }^{36}$ and 76 percent of the community GDPs and 29 per- cent of the private GDPs in Sweden. ${ }^{37}$ Some dentists who participated in the study commented that wearing masks is not as critical as wearing gloves in dental treatment. All dentists changed saliva ejectors, and almost 96 percent changed burs and extraction instruments between patients. ${ }^{34}$ Although these precautions should be standard procedure for dentists, there were still about 4 percent of dentists, primarily older practitioners, who thought that cleaning burs and instruments with a disinfectant before providing dental treatment for other patients was satisfactory. This finding demonstrates the lack of awareness about cross infection, particularly among dentists who graduated from dental school many years ago. 


\section{Control measures}

American Dental Association (ADA) requires the adoption of the concept of universal precautions (a set of cross-infection measures for all the patients, considering every patient as possibly infectious). All personnel involved in the practice of dentistry must understand the risk involved, and should fully conversant with the procedures employed in cross-infection control. One exception to the concept of universal precautions is the treatment of potential carries of transmissible spongiform encephalopathy (TSE). The transmissible agents thought to be responsible for this disease are proteins called prions. In order to destroy prions, steam sterilization for 18 minutes is recommended. The alternative is to destroy all instruments used on a patient suspected of carrying TSE. In practice there are very few patients in this category, and so apart from the sterilization procedures called universal precautions fro cross-infection. At present there is no evidence that TSE could be transmitted by simple dental procedures. ${ }^{[38]}$

The universal infection control rules should encompass six aspects: routine patient evaluation, personal protection with barrier techniques, instrument sterilization - including sterilization control, surface and equipment disinfecting, asepsis in the laboratory and appropriate disposal of contaminated waste including sharps. ${ }^{[38]}$ Disinfection is defined as the removal or killing of all pathogens, but not spores. Ideally, all vegetative microbes should be killed, but a reduction in the number of pathogens to a level that is unlikely to cause infection is acceptable. The methods of disinfection are heating (by Pasteurization or by boiled in water), using ultrasonic, or using chemical solutions. ${ }^{[38]}$

Impressions are a potential vehicle in transmission of infectious agents. Moreover, casts produced from contaminated impressions may themselves be contaminated because microorganisms are able to migrate from the impressions into the casts, while setting occurs [39] The disinfection of impressions, and other laboratory fabricated material, is more difficult and requires immersion. The agent chosen must have a deleterious effect on the dimensional stability of hydrocolloids, and must act in a reasonable time (in practice this is about 15-30 minutes). Irreversible hydrocolloid is capable of resisting contamination by viruses and saliva when the disinfectant iodine or chlorhexidine is added to the water being used to mix the material. Accurate casts can be obtained when either of the two disinfectants is incorporated into the alginate impression material. ${ }^{[40]}$

In this study, $80 \%$ of dentists preferred to clean handpieces by wiping them with disinfectants, but only $17.8 \%$ of them stated that they preferred autoclave for sterilize handpieces. [41] However, it is known live blood cells and bacterial and viral particles can survive inside handpieces even after thorough disinfection. ${ }^{[42]}$ The use of non-disposable syringes means that needles must be re-sheathed in order for the syringes to be dismantled and the appropriate parts autoclaved. It is during re-sheathing and disposal of the needles that the majority of needle stick injuries occur, especially when done frequently in an environment with trainees and students. ${ }^{[43]}$ The injuries occur at a time when the syringes are most likely to be contaminated, having been in the patient's mouth. It is well known that needle stick injuries can result in transmission of blood borne viruses, including HIV, hepatitis B and C. A survey of occupational injuries in a London teaching hospital in 1994 showed that $7 \%$ of exposures involving blood or body fluids were positive for at least one blood borne virus. ${ }^{[44]}$

Nosocomial or hospital acquired infections are today by far the most common complications affecting hospitalized patients. Indeed the Harvard Medical Practice Study II found that a single type of nosocomial infection, surgical infection constituted the second largest category of adverse events. Currently between 5 and $10 \%$ of patients admitted to acute care hospitals acquire one or more infections and the risks have steadily increased during recent decades. Four types of infections account for more than $80 \%$ of all nosocomial infections. They are urinary tract infection, surgical site infection, bloodstream infection and pneumonia. One fourth of nosocomial infections include patients in intensive care units and nearly $70 \%$ are due to microorganisms that are resistant to one or more antibiotics. ${ }^{[45]}$

\section{References}

1. Mutlu S, Porter SR, Scully C. Cross-infection control in dentistry. Erofset, Istanbul, Turkey; 1996.

2. Adel A Mousa, Nadia M Mahmoud, Azza M Tag ElDin. Knowledge and attitudes of dental patients towards cross infection control measures in dental practice. Eastern Mediterranean Health Journal, Vol.3, No.2, 1997

3. Samaranayke, L., (1993).Rules of infection control. Int Dent J43(6): 578-584.

4. Bolyard EA, Tablan OC, Williams WW, Pearson ML, Shapiro CN, Deitchman SD. Guideline for infection control in health care personnel, 1998. Hospital Infection Control Practices Advisory Committee. Am J Infect Control. 1998; 26:289-354.

5. Merchant VA. Herpesvirus and other micro-organisms of concern in dentistry. Dent Clin North Am. 1991;35:283-98

6. Mori M. Status of viral hepatitis in the world community: its incidence among dentists and other dental personnel. Int Dent J. 1984; 34:115-21.

7. Morris E, Hassan FS, Al Nafisi A, Sugathan TN. Infection control knowledge and practices in Kuwait: a survey on oral health care workers. Saudi Dent J. 1996; 8:19-26.

8. Mutlu S, Porter SR, Scully C. Cross-infection control in dentistry. Erofset, Istanbul, Turkey; 1996.

9. Panis B, Roumeliotou-Karayannis A, Papaevangelou G, Richardson SC, Mitsis F. Hepatitis B virus infection in dentists and dental students in Greece. Oral Surg Oral Med Oral Pathol. 1986; 61:343-5.

10. Klein RS, Freeman K, Taylor PE, Stevens CE. Occupational risk for hepatitis $\mathrm{C}$ virus infection among New York City dentists. Lancet. 1991; 338:1539-42.

11. Thomas DL, Gruninger SE, Siew C, Joy ED, Quinn TC. Occupational risk of hepatitis $\mathrm{C}$ infections among general dentists and oral surgeons in North America. Am J Med. 1996; 100:41-5.

12. Reinthaler F, Mascher F, Stunzner D. Serological examinations for antibodies against Legionella species in dental personnel. J Dent Res. 1998;67:942-3)

13. Davies KJ, Herbert AM, Westmoreland D, Bagg J. Seroepidemiological study of respiratory virus 
infections among dental surgeons. Br Dent J. 1994; 176:262-5.

14. Allsopp J, Basu MK, Browne RM, Burge PS, Matthews JB. Survey of the use of personal protective equipment and prevalence of work related symptoms among dental staff. Occup Environ Med. 1997; 54:12534.

15. Atlas RM, Williams JF, Huntington MK. Legionellacontamination of dental-unit waters. Appl Environ Microbiol 1995; 61:1208-13.

16. Pankhurst CL, Philpott-Howard JN. The microbiological quality of water in dental chair units. $J$ Hosp Infect 1993; 23: 167-74.

17. Williams JF, Johnston AM, Johnson B, et al. Microbial con- tamination of dental unit waterlines. $J$ Am Dent Assoc 1993; 124:59-65.

18. Shearer BG. Biofilm and the dental oYce. J Am Dent Assoc 1996; 19:181-9.

19. MMWR Morbid Mortal Wkly Rep1990; 39:489-93.

20. Centers for Disease Control and Prevention. Update: trans- mission of HIV infection during invasive dental procedures-Florida. MMWR Morbid Mortal Wkly Rep 1991; 40:377-81.

21. Robinson, P., Challacombe, S., (1993). Transmission of HIV in a dental practice - the facts. Br. Dent $J$ 10:383-384.

22. Cash RG. Sterilisation and disinfection procedures.A Survey of Georgia Orthodontists. J.ClinOrthodn 1988 22: $22-28$

23. O O Sofola, O G Uti and O OOnigbinde Lagos, Nigeri.Public perception of cross-infection control in dentistry in Nigeria. International Dental Journal (2005) 55, 383-387

24. Gerbert B. AIDS and infection control in dental practice: dentists attitude, knowledge and behaviour. $J$ Am Dent Assoc 1987 114: 311-314.

25. DiAngelis AJ, Martens LV, Little JW et al. Infection control practices of Minnesota dentists: changes during 1 year. J Am Dent Assoc 1989 118: 299-303.

26. Preston A, Littleton Jr, Kohn WG. Dental public health and infection control in industrialised and developing countries. Int Dent J 1991 41: 341-347.

27. Wood PR. A practical gloving and handwashing regimen for dental practice. Br Dent J. 1992; 172:3678.

28. Centers for Disease Control and Prevention. Recommended infection-control practices for dentistry. MMWR Morbid Mortal Wkly Rep1993; 42:1-12.

29. Morris E, Hassan FS, Al Nafisi A, Sugathan TN. Infection control knowledge and practices in Kuwait: a survey on oral health care workers. Saudi Dent J 1996; 8:19-26.

30. Nash KD. How infection control procedures are affecting dental practice today. $J$ Am Dent Assoc 1992;123:67-73
31. Angelillo IF, Villari P, D’Errico MM, Grasso GM, Ricciardi G, Pavia M. Dentists and AIDS: a survey of knowledge, attitudes and behaviour in Italy. J Public Health Dent 1994; 54:145-52.

32. McCarthy GM, MacDonald JK. A comparison of infection control practices of different groups of oral special- ists and general dental practitioners. Oral Surg Oral Med Oral Pathol Oral RadiolEndod 1998;85:4754.

33. Al-Rabeah A, Mohamed AGI. Infection control in the private dental sector in Riyadh. Ann Saudi Med 2002;22:1-2.

34. Compliance with Infection Control Programs in Private Dental Clinics in Jordan .Mohammad Ahmad AlOmari, B.D.S., M.S.C., Ph.D., F.F.D.R.D.C.I.; ZiadNawaf Al-Dwairi, B.D.S., Ph.D.

35. Treasure P, Treasure ET. Survey of infection control procedures in New Zealand dental practices. Int Dent $J$ 1994;44:342-8.

36. McCarthy GM, MacDonald JK. The infection control practices of general dental practitioners. Infect Control HospEpidemiol 1997; 18:699-703.

37. Hellgren K. Use of gloves among dentists in Sweden: a three-year follow-up study. Swed Dent J 1994; 18:9-14.

38. Carmen Elena Georgescu, n. Skaug, i. Patrascu. Cross Infection in Dentistry. Roum. Biotechnol. Lett., Vol. 7, No. 4, 861-868 (2002)

39. Flanagan, d., A., Palenik, C., J., Setcos, J., C., Sheldrake, M., A., Miler, C., H., (1998). Antimicrobial activities of dental impression materials. Dent Mater $J$ 14:399-404)

40. Huizing, K., L., Palenik, C., J., Setcos, J., C., Sheldrake, M., A., Miler, C., H., (1994). A method to evaluate the anti-microbial abilities of disinfectantcontaining gypsum products. QDT Yearbook 17:172176.)

41. Emir Yüzbasioglu, Duygu Saraç, Sevgi CANBAZ, Y. Sinasi SARAÇ, Seda Cengiz.A Survey of CrossInfection Control Procedures: Knowledge And Attitudes of Turkish Dentists. J Appl Oral Sci. 2009; 17(6):565-9

42. Lewis DL, Arens M, Appleton SS, Nakashima K, Ryu $\mathrm{J}$, Boe RK, et al. Cross-contamination potential with dental equipment. Lancet. 1992;340:1252- 4

43. McDonald R I, Walsh L J, Savage N W. Analysis of workplace injuries in a dental school environment. Aust.Dent.J.1997; 42:109-113.)

44. Gyawali P, Rice P S, Tilzey A J. Exposure to blood borne viruses and the hepatitis $\mathrm{B}$ vaccination status among healthcare workers in inner London. Occup Environ Med 1998; 55:570-572.)

45. Burke, John P. Infection Control - A Problem for Patient Safety. The New England Journal of Medicine; Boston 348.7 (Feb 13, 2003): 651-6

\section{How to cite this article:}

Anisha Mahtani and Gopinath P (2017) ' A Review On Cross Infection In Dental Clinics', International Journal of Current Advanced Research, 06(04), pp. 3333-3336.

DOI: http://dx.doi.org/10.24327/ijcar.2017.3336.0265 